\title{
The Differential Effects of Erythropoietin Exposure to Oxidative Stress on Microglia and Astrocytes in vitro
}

\author{
Praneeti Pathipati Donna M. Ferriero \\ Department of Pediatrics, University of California San Francisco, San Francisco, CA, USA
}

\section{Keywords}

Glia $\cdot$ Hydrogen peroxide $\cdot$ Injury $\cdot$ Neuroinflammation

\section{Abstract}

The neonatal brain is especially susceptible to oxidative stress owing to its reduced antioxidant capacity. Following hypoxic-ischemic ( $\mathrm{HI})$ injury, for example, there is a prolonged elevation in levels of hydrogen peroxide $\left(\mathrm{H}_{2} \mathrm{O}_{2}\right)$ in the immature brain compared to the adult brain, resulting in lasting injury that can lead to life-long disability or morbidity. Erythropoietin (Epo) is one of few multifaceted treatment options that have been promising enough to trial in the clinic for both term and preterm brain injury. Despite this, there is a lack of clear understanding of how Epo modulates glial cell activity following oxidative injury, specifically, whether it affects microglia (Mg) and astrocytes (Ast) differently. Using an in vitro approach using primary murine $\mathrm{Mg}$ and Ast subjected to $\mathrm{H}_{2} \mathrm{O}_{2}$ injury, we studied the oxidative and inflammatory responses of $\mathrm{Mg}$ and Ast to recombinant murine (rm)Epo treatment. We found that Epo protects Ast from $\mathrm{H}_{2} \mathrm{O}_{2}$ injury $(p<0.05)$ and increases secreted nitric oxide levels in these cells $(p<0.05)$ while suppressing intracellular reactive oxygen species $(p<0.05)$ and superoxide ion $(p<$ 0.05 ) levels only in Mg. Using a multiplex analysis, we noted
\end{abstract}

\section{KARGER}

(๑) 2017 S. Karger AG, Basel

E-Mail karger@karger.com

www.karger.com/dne that although $\mathrm{H}_{2} \mathrm{O}_{2}$ induced the levels of several chemokines, rmEpo did not have any significant specific effects on their levels, either with or without the presence of conditioned medium from injured neurons (NCM). Ultimately, it appears that rmEpo has pleiotropic effects based on the cell type; it has a protective effect on Ast but an antioxidative effect only on Mg without any significant modulation of chemokine and cytokine levels in either cell type. These findings highlight the importance of considering all cell types when assessing the benefits and pitfalls of Epo use.

(c) 2017 S. Karger AG, Basel

Injury to the developing brain is a leading cause of neurodevelopmental disabilities, resulting in life-long morbidity in survivors, with hypoxic-ischemic (HI) damage being the most common cause of brain injury among newborns $[1,2]$. We previously reported that the developing brain is particularly sensitive to oxidative injury [3] and experiences a greater accumulation of hydrogen peroxide $\left(\mathrm{H}_{2} \mathrm{O}_{2}\right)$ following $\mathrm{HI}$ injury compared to the adult brain [4]. This $\mathrm{H}_{2} \mathrm{O}_{2}$ subsequently combines with the free iron in the immature brain, producing damaging free radicals that disrupt key cellular processes that lead to cell death. While several antioxidative treatments have shown

Praneeti Pathipati

Department of Pediatrics, University of California San Francisco UCSF Mission Bay, 675 Nelson Rising Lane, Rm494

San Francisco, CA 94143 (USA)

E-Mail praneetipathipati@gmail.com 
promise over the years, none of them is yet clinically acceptable due to the uncertainty about their beneficial effects [5]. Consequently, there is an unmet need for treatment options for HI brain injury that address oxidativestress-induced $\mathrm{HI}$ damage along with other effects such as inflammation, cell death, and repair.

Erythropoietin (Epo) is a hematopoietic cytokine with an established role in neuroprotection. Although it is primarily produced in the kidneys and liver, studies also show the expression of Epo receptor and Epo production in the brain early in development $[6,7]$. Epo production is evident primarily in astrocytes (Ast) [8], and to a lesser extent in neurons [9] and oligodendrocytes $[8,10]$, where it occurs in a regulated manner. All these cells, along with microglia (Mg) [11], also express Epo receptor and see an upregulation after injury [12], suggesting that Epo has a role in postinjury processes in the brain. Indeed, several lines of evidence, both in vivo and in vitro, have now established that Epo has important neuroprotective, neurogenic, angiogenic, and oligodendrogliogenic properties after HI $[10,13,14]$. Promising clinical trials with Epo as a potential treatment for preterm and term brain injury are currently underway [15].

Despite its promise as a potential treatment for $\mathrm{HI}$ injury, there are currently limited data on the specific effects of Epo on oxidative and inflammatory responses after $\mathrm{HI}$ injury, especially in glial cells. While some evidence suggests that Epo has antiapoptotic, antioxidative, and antiinflammatory effects on Ast and $\mathrm{Mg}$ [16], few reports exist of posttreatment with Epo, and even fewer report Epo effects after a direct oxidative insult on these cells. Moreover, closer analysis of the literature suggests that Epo can have differential effects on different cell types [16], highlighting the importance of understanding the timing and pattern of these responses in determining effective dosing strategies for clinical trials.

The aim of this study was to characterize the oxidative and inflammatory responses of Ast and $\mathrm{Mg}$ to exogenous Epo following an oxidative insult utilizing $\mathrm{H}_{2} \mathrm{O}_{2}$ exposure as the model of oxidative stress injury in vitro. We have previously shown that $\mathrm{H}_{2} \mathrm{O}_{2}$ levels in the immature (but not adult) brain are sustained at high levels after injury for at least 5 days [17], rendering it highly susceptible to oxidative injury over a prolonged period. In order to mimic this in vitro, we utilized an enzymatic system where we used glucose oxidase and catalase to generate and break down (respectively) $\mathrm{H}_{2} \mathrm{O}_{2}$ and maintain it at a constant level $[18,19]$. We have previously shown that this system can be successfully used in vitro on $\mathrm{Mg}$ to induce oxidative and inflammatory responses [18]. Here,

Erythropoietin and Microglia and Astrocytes we extend this analysis to cultured Ast, examine the responses after treatment with Epo, and show that Epo has differential, pleiotropic effects on $\mathrm{Mg}$ and Ast.

\section{Experimental Procedures}

\section{Materials}

The following reagents were all sourced from the Cell Culture Facility at the University of California San Francisco, CA, USA: Hanks' balanced salt solution, Dulbecco's modified Eagle's medium (DMEM; phenol red-free, $4.5 \mathrm{~g} / \mathrm{L}$ glucose, with no pyruvate), penicillin-streptomycin (P/S), fetal bovine serum (FBS; Axenia Biologix), and $0.05 \%$ trypsin. Glucose oxidase (GOX, G0543), catalase (CAT, C3155), $\mathrm{H}_{2} \mathrm{O}_{2}$ (H1009), and H2DCFDA (\#D6883) were from Sigma (St. Louis, MO, USA). Neurobasal (NB) medium (12348-017), B27 (17504044), B27 without antioxidants (10889038), GlutaMax I (35050), Griess reagent (G7921), Live-Dead Assay (L3224), and the LDH cytotoxicity kit (11644793001) were from Roche. Recombinant murine (rm)Epo (959-ME-010) was from R\&D Systems (reconstituted in $0.1 \%$ BSA PBS).

\section{$\mathrm{Mg}$ and Ast Cultures and $\mathrm{H}_{2} \mathrm{O}_{2}$ Treatment}

Animals were sacrificed in accordance with guidelines from the Institutional Animal Care and Use Committee at the University of California San Francisco, CA, USA. Mixed glial cultures were prepared from P1 C57BL/6 mice (Simonsen Laboratories, Gilroy, CA, USA). Their brains were isolated, stripped of meninges, mechanically dissociated, and trypsinized for $15 \mathrm{~min}$ at $37^{\circ} \mathrm{C}$. Following resuspension in DMEM supplemented with $1 \% \mathrm{P} / \mathrm{S}$ and $10 \%$ FBS, cells were seeded ( 2 brains/T-75 flask) and then incubated at $37^{\circ} \mathrm{C} / 5 \% \mathrm{CO}_{2}$. Medium was changed the next day and then every 3 days subsequently. After 10-14 days, the flasks containing mixed glial cultures were shaken for $1-2 \mathrm{~h}$ at $200 \mathrm{rpm}$ and $37^{\circ} \mathrm{C}$ to lift off the microglial cells, which were then plated into 24-well plates in DMEM supplemented with $1 \% \mathrm{P} / \mathrm{S}$ and $2 \%$ FBS overnight and used the next day. Cells from a $75-\mathrm{cm}^{2}$ flask were seeded into a 24-well plate. Ast contamination in $\mathrm{Mg}$ cultures was confirmed to be $<5 \%$ using immunofluorescence (Iba-1 for Mg, glial fibrillary acid protein for Ast, and $\mathrm{O}_{4}$ for oligodendrocyte labeling; data not shown).

Following $\mathrm{Mg}$ isolation, the flasks were replenished with fresh DMEM supplemented with $1 \% \mathrm{P} / \mathrm{S}$ and $10 \%$ FBS, sealed with Parafilm, and shaken for $24 \mathrm{~h}$. The medium was replaced again, and the flasks resealed and shaken for another $24 \mathrm{~h}$ until no phase-dark cells (oligo-

Dev Neurosci 2017;39:310-322

DOI: $10.1159 / 000467391$ 
dendroglia) were visible. Ast were then trypsinized with $0.05 \%$ trypsin, pelleted, and plated into 24 -well plates at a density of 250,000 cells/well overnight and used the next day. The Mg contamination of Ast cultures was established to be $<5 \%$ as confirmed by immunocytochemistry (Iba-1 for Mg, glial fibrillary acid protein for Ast, and $\mathrm{O}_{4}$ for oligodendrocyte labeling; data not shown).

\section{$\mathrm{Mg}$ and Ast Stimulation with $\mathrm{H}_{2} \mathrm{O}_{2}$ and Treatment with $r m E P O$}

The GOX-CAT method is an enzymatic method that can be used to generate low, continuous $\mathrm{H}_{2} \mathrm{O}_{2}$ for over 24 $\mathrm{h}[18,19]$. GOX is a stable enzyme that remains fully active over $24 \mathrm{~h}$ at $37^{\circ} \mathrm{C}$ and generates $\mathrm{H}_{2} \mathrm{O}_{2}$ by consuming $\mathrm{O}_{2}$, while CAT degrades $\mathrm{H}_{2} \mathrm{O}_{2}$ back to $\mathrm{H}_{2} \mathrm{O}$ and $\mathrm{O}_{2}$ and is not saturable, even at molar concentrations of $\mathrm{H}_{2} \mathrm{O}_{2}$. This means that while GOX generates $\mathrm{H}_{2} \mathrm{O}_{2}$ over $24 \mathrm{~h}$, CAT continuously breaks it down in a typical exponential kinetic fashion that is directly dependent on the $\mathrm{H}_{2} \mathrm{O}_{2}$ concentration. Accordingly, stable $\mathrm{H}_{2} \mathrm{O}_{2}$ concentrations are generated that only depend on the ratio of enzyme activities. Thus, by regulating the specific dilutions of CAT (and thus the rate of $\mathrm{H}_{2} \mathrm{O}_{2}$ breakdown) in the medium, it is possible to produce controlled amounts of $\mathrm{H}_{2} \mathrm{O}_{2}$ continuously for at least $24 \mathrm{~h}$ within a variability of $20 \%$. No significant hypoxia is induced for 24-well plates using a GOX activity of 1:100,000 and a medium volume of $0.5 \mathrm{~mL}$ [19].

The aims of the experiments were to study the responses of these cell types to low and high continuous exposures of $\mathrm{H}_{2} \mathrm{O}_{2}$. The low and high doses for each of the cell types was determined from titration studies where the dose eliciting minimal, i.e., $\leq 2$-fold of control cell death, was considered a low dose, and that 2 - to 4 -fold of control cell death was equated as a high dose, as measured at 24 $\mathrm{h}$ after exposure. In all experiments, GOX was kept at a constant dilution of 1:100,000, whereas CAT dilution varied (1:20,000 [low], 1:960,000 [high for $\mathrm{Mg}$ ]/1: $1,280,000$ [high for Ast]) resulting in $\mathrm{H}_{2} \mathrm{O}_{2}$ levels of around 1-3 $\mu$ M. Since serum can contain CAT, all $\mathrm{H}_{2} \mathrm{O}_{2}$ treatments were carried out in serum-free DMEM (DMEM SF) with $1 \% \mathrm{P} / \mathrm{S}$. DMEM SF served as a control for the $\mathrm{H}_{2} \mathrm{O}_{2}$ treatments. Following overnight plating in $2 \%$ FBS DMEM, the medium in the plates was replaced with prewarmed test medium (containing GOX-CAT/ control) for $4 \mathrm{~h}$. At $4 \mathrm{~h}, \mathrm{rmEpo}$ was added into the medium at a final concentration of $10 \mathrm{ng} / \mathrm{mL}$ in DMEM SF (a volume of $10 \mu \mathrm{L}$ ), with the dose chosen based on previously published data showing this to be an effective dose for eliciting cellular effects [20,21]; $10 \mu \mathrm{L}$ DMEM SF was added into the non-Epo control wells at the same time.
All assays were run in duplicate and repeated independently 6 times. Experiments were ended $20 \mathrm{~h}$ later $(24 \mathrm{~h}$ from the start of $\mathrm{H}_{2} \mathrm{O}_{2}$ treatment). For pretreatment studies, cells were exposed to $10 \mathrm{ng} / \mathrm{mL}$ Epo for $24 \mathrm{~h}$ prior to $\mathrm{H}_{2} \mathrm{O}_{2}$ exposure for $2 \mathrm{~h}$.

\section{In vitro Assays}

All in vitro assays were carried out at the end of the study ( $24 \mathrm{~h}$ from the start of $\mathrm{H}_{2} \mathrm{O}_{2}$ treatment and $20 \mathrm{~h}$ from Epo addition), unless otherwise stated.

\section{Viability Assay}

$\mathrm{Mg}$ and Ast viability in response to $\mathrm{H}_{2} \mathrm{O}_{2}$ treatment were assessed using the LDH assay according to the manufacturer's instructions. LDH release into the medium was compared to total LDH in the medium following cell lysis. For pretreatment studies, LDH release was measured at the end of $2 \mathrm{~h}$ of $\mathrm{H}_{2} \mathrm{O}_{2}$ exposure.

\section{Nitrite Assay}

Nitrite levels in medium were used as a surrogate measure of nitric oxide (NO) using the Griess reagent according to the manufacturer's protocols. Briefly, at the end of the designated time period, $150 \mu \mathrm{L}$ of medium from each well was mixed with $20 \mu \mathrm{L}$ of Griess reagent and $130 \mu \mathrm{L}$ of deionized water for $30 \mathrm{~min}$ at room temperature. Absorbance was measured and expressed relative to the reference (sodium nitrite) sample at $548 \mathrm{nM}$ after normalizing to the amount of protein in the well.

\section{Reactive Oxygen Species Assay}

Cellular reactive oxygen species (ROS) content was measured using the H2DCFDA reagent. At the end of the designated time period, cells were loaded with $20 \mu \mathrm{M}$ H2DCFDA for $45 \mathrm{~min}$ at $37^{\circ} \mathrm{C}$. Following 2 washes with prewarmed Hanks' balanced salt solution, fluorescence absorption was measured at $485^{\mathrm{ex}} / 535^{\mathrm{em}} \mathrm{nm}$. Results were normalized to the amount of protein in the well.

\section{Mitochondrial Superoxide Assay}

Mitochondrial superoxide levels were measured using MitoSOX Red indicator dye. As it is readily oxidized by superoxide but not by other ROS-/reactive nitrogen species-generating systems, it would give an accurate measure of superoxide levels in response to $\mathrm{H}_{2} \mathrm{O}_{2}$ treatment. At the end of the time period, cells were loaded with $5 \mu \mathrm{M}$ MitoSOX dye in prewarmed DMEM SF for $10 \mathrm{~min}$ at $37^{\circ} \mathrm{C}$. Following 2 washes in the same medium, fluorescence absorption was measured at $485^{\mathrm{ex}} / 590^{\mathrm{em}} \mathrm{nm}$, and results were normalized to the amount of protein in the well.
Pathipati/Ferriero 
Fig. 1. $\mathrm{H}_{2} \mathrm{O}_{2}$-induced $\mathrm{LDH}$ release is not attenuated by treament with rmEpo at $4 \mathrm{~h}$. Cultured primary murine astrocytes (Ast) and microglia (Mg) were exposed to continuous $\mathrm{H}_{2} \mathrm{O}_{2}$ for $4 \mathrm{~h}$ before treatment with $10 \mathrm{ng} / \mathrm{mL}$ rmEpo. LDH release into the medium was measured after $20 \mathrm{~h}$ of Epo treatment (24 h after the start of $\mathrm{H}_{2} \mathrm{O}_{2}$ injury). $\mathrm{Mg}$ (a) and Ast (b) LDH release. Pretreament $(1 \mathrm{~h})$ with $10 \mathrm{ng} / \mathrm{mL}$ Epo before administering $\mathrm{H}_{2} \mathrm{O}_{2}$ for $2 \mathrm{~h}$ elicited protection in Ast (d) but not in $\mathrm{Mg}(\mathbf{c})$. Results are a composite of at least 6 (posttreatment) and 3 (pretreatment) independent assays. ${ }^{*} p<0.05,{ }^{* *} p<0.01,{ }^{* * *} p<0.0001$ versus control.
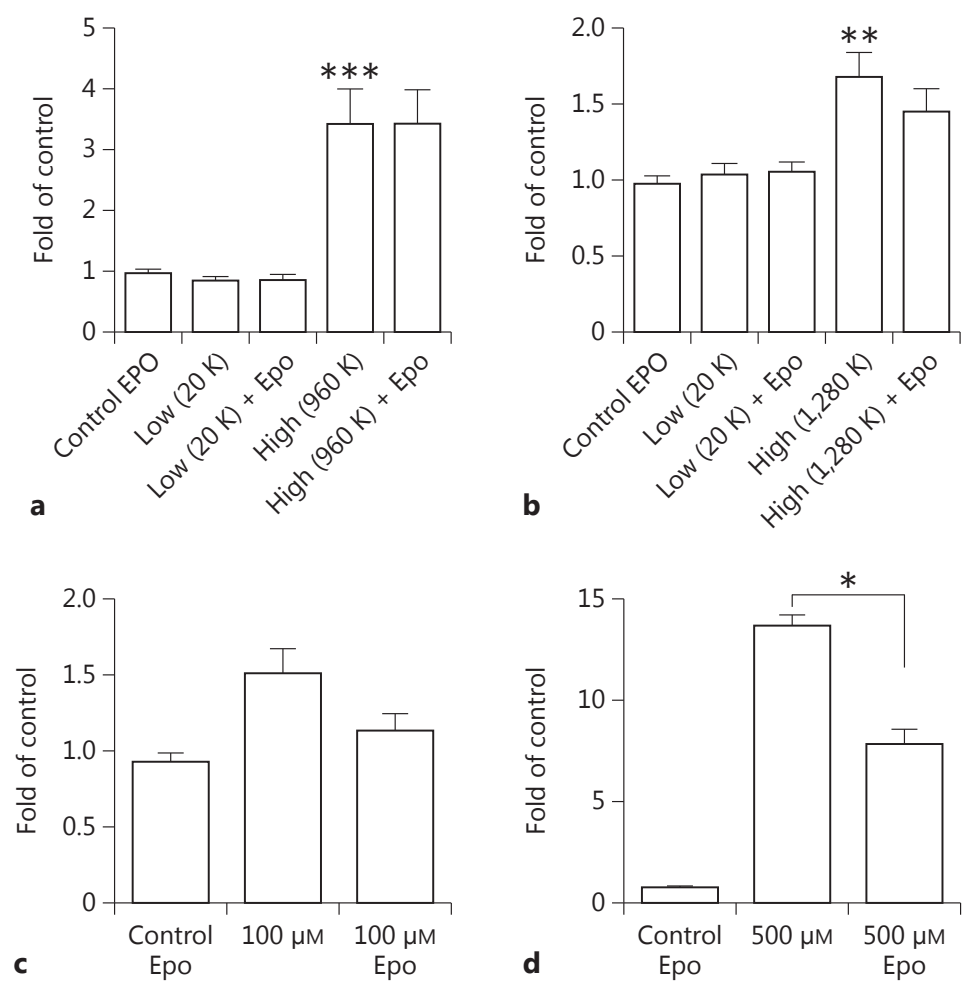

\section{Multiplex Assay for Cytokine Measurements}

Cytokine protein expression in $\mathrm{Mg}$-/Ast-conditioned medium was assessed according to the manufacturer's instructions on a custom mouse 15-plex cytokine MicroBead assay kit which allows for the simultaneous detection of 15 inflammatory molecules in a single $75-\mu \mathrm{L}$ sample including KC, MCP-1, MIP-1 $\alpha$, MIP-1 $\beta$, MIP-2, RANTES, G-CSF, IL-1a, IL-1b, IL-4, IL-6, IL-9, IL-10, IL13, and TNFa. Results were analyzed using a Bio-Plex workstation (Bio-Rad), and then levels were normalized to the total amount of protein in the appropriate well and subsequently expressed as fold of control. For discussion purposes, KC, MCP-1, MIP-1 $\alpha$, MIP-1 $\beta$, MIP-2, and RANTES were loosely categorized as chemokines, with the remainder classified as cytokines. Protein concentrations were determined using the Bio-Rad DC protein assay. Data are expressed as picograms per microgram of protein. The level of sensitivity for each MicroBead cytokine standard curve ranged from 1 to $35 \mathrm{pg} / \mathrm{mL}$. Two 96well assays were performed in duplicate, with each plate containing Mg-/Ast-conditioned medium from 6 independent experiments. For neuron-conditioned medium
(NCM) studies, medium from 3 independent experiments was assessed.

\section{Primary Cortical Neuronal Culture and Generation of NCM}

Cultures were prepared from the cortices of embryonic day 15 C57BL/6 mice as previously described [22]. Briefly, embryos were harvested from the dam under terminal anesthesia, and the cortices were isolated, papain digested, and plated onto PDL-pre-coated 24-well plates in NB medium. On day 3 in vitro (DIV3), AraC was added to a final concentration of $5 \mu \mathrm{M}$, and on DIV4, half of the medium was exchanged for fresh NB medium with B27-antioxidants. Experiments were initiated on DIV6 when medium was replaced with fresh NB medium with B27-antioxidants containing $50 \mu \mathrm{M} \mathrm{H}_{2} \mathrm{O}_{2}$ (or just NB-antioxidants for control) for $30 \mathrm{~min}$. At the end of $20 \mathrm{~min}$, the NCM was collected and centrifuged at $5,000 \mathrm{rpm}$ for $5 \mathrm{~min}$ at $4^{\circ} \mathrm{C}$ before storage at $-80^{\circ} \mathrm{C}$ until use. On the day of use, NCM was thawed on ice and concentrated using 3,000-Da molecular-weight cut-off filters (UFC800324, Millipore). $50 \mu \mathrm{L}$ of concentrated 
$\mathrm{NCM}$ was added per well to the Ast or Mg culture, at the same time as $\mathrm{H}_{2} \mathrm{O}_{2}$.

\section{Statistics}

All statistical analyses were performed using GraphPad Prism v5.0 (La Jolla, CA, USA). Wilcoxon signedrank tests were used to compare treatments with and without rmEpo and to control on data normalized to the protein content for each respective treatment well. All results are expressed as means \pm SEM and significance was accepted at $p \leq 0.05$.

\section{Results}

\section{Viability}

Epo has been shown to be protective in a range of experimental paradigms. Here, we tested the neuroprotective capacity of rmEpo following $\mathrm{H}_{2} \mathrm{O}_{2}$ injury in primary $\mathrm{Mg}$ and Ast using LDH release as a measure.

As expected, $\mathrm{H}_{2} \mathrm{O}_{2}$ exposure induced significant cell death at the higher concentrations for both cell types $(p<$ 0.0001 ; Fig. 1a-d). The addition of $10 \mathrm{ng} / \mathrm{mL} \mathrm{rmEpo}$ following a 4-h $\mathrm{H}_{2} \mathrm{O}_{2}$-induced injury did not appear to be protective in either cell type (Fig. 1a-d), but when pretreated for $24 \mathrm{~h}$ with rmEpo, protection was seen in Ast $(p<0.05$; Fig. 1f) but not in Mg (Fig. 1e).

\section{Oxidative Stress}

\section{Nitrites}

The effects of Epo on NO production/nitrite levels in cultured cells vary and appear to be largely due to factors like which type of cell or stimulus is involved [16]. We tested whether rmEpo would alter nitrite levels in cultured $\mathrm{Mg}$ and Ast stimulated with $\mathrm{H}_{2} \mathrm{O}_{2}$.

There were no significant changes in nitrite levels in $\mathrm{Mg}$ with either $\mathrm{H}_{2} \mathrm{O}_{2}$ or rmEpo treatment (Fig. 2a). In Ast, however, nitrite levels were considerably suppressed after $\mathrm{H}_{2} \mathrm{O}_{2}$ (Fig. 2b), and following rmEpo treatment, they were significantly increased (Fig. $2 \mathrm{~b}, p<0.05$ and $p<0.01$, respectively, for low and high continuous $\mathrm{H}_{2} \mathrm{O}_{2}$ ).

\section{Reactive Oxidative Species}

Epo has been widely reported to have antioxidative properties. However, most in vitro studies utilize a pretreatment paradigm. The aim of our study was to evaluate the posttreatment effects of rmEpo on the intracellular levels of ROS.

In $\mathrm{Mg}$, low-dose $\mathrm{H}_{2} \mathrm{O}_{2}$ significantly increased ROS levels, and rmEpo treatment significantly suppressed the flu- orescence of high continuous $\mathrm{H}_{2} \mathrm{O}_{2}$ cultures (Fig. $2 c ; p<$ 0.05 ) but had no effect on low $\mathrm{H}_{2} \mathrm{O}_{2}$ cultures. In Ast, there were no significant changes in ROS levels with either $\mathrm{H}_{2} \mathrm{O}_{2}$ or rmEpo treatment (Fig. 2d).

Superoxide

In order to understand if Epo would mediate antioxidative mechanisms via superoxide production, we examined MitoSOX fluorescence in glial cells after rmEpo treatment following $\mathrm{H}_{2} \mathrm{O}_{2}$ injury.

While no significant changes were seen with $\mathrm{H}_{2} \mathrm{O}_{2}$ treatment in $\mathrm{Mg}$, rmEpo led to significant suppression of indicator levels in high continuous $\mathrm{H}_{2} \mathrm{O}_{2}$ cultures (Fig. 2e; $p<0.05)$. In Ast cultures, no significant changes in MitoSOX indicator levels were seen with either $\mathrm{H}_{2} \mathrm{O}_{2}$ or rmEpo treatment (Fig. 2f).

\section{Inflammatory Responses}

Both $\mathrm{Mg}$ and Ast mediate neuroinflammation via cytokine and chemokine release. We analyzed the cytokine and chemokine secretion profile for both $\mathrm{Mg}$ and Ast following rmEpo treatment of $\mathrm{H}_{2} \mathrm{O}_{2}$-induced injury.

Overall, significant changes were evident in chemokine levels in $\mathrm{Mg}$. Low $\mathrm{H}_{2} \mathrm{O}_{2}$ caused an increase in the levels of MIP-2 and RANTES ( $p<0.05$; Fig. $3 g$, h), with a similar trend but failing to reach significance in TNFa and MIP- $1 \alpha$ ( $p=0.06$; Fig. 3a, c). High continuous $\mathrm{H}_{2} \mathrm{O}_{2}$ suppressed MIP-1 $\alpha$, MIP- $1 \beta$, and RANTES $(p<0.05$; Fig. $3 c, e, h)$. rmEpo treatment did not have any significant effects. There were no significant changes in any inflammatory mediator levels in Ast (Fig. 4).

\section{Neuron-Conditioned Medium}

Since cytokine/chemokine responses to $\mathrm{H}_{2} \mathrm{O}_{2}$ did not seem to be significantly altered by rmEpo in most of the paradigms tested, we speculated that the presence of at least signaling molecules from injured neurons might be necessary for glial cells to elicit significant secretory responses. To this end, we exposed cortical neurons to 30 min of $50 \mu \mathrm{M} \mathrm{H}_{2} \mathrm{O}_{2}$, and transferred this NCM to Mg and Ast at the same time as $\mathrm{H}_{2} \mathrm{O}_{2}$ was added. Results are shown only for cytokines/chemokines exhibiting considerable changes.

Overall, there were no significant changes with the addition of NCM along with $\mathrm{H}_{2} \mathrm{O}_{2}$, nor were there any significant effects of rmEpo on chemokine/cytokine levels in either cell type (Fig. 5, Mg; Fig. 6, Ast). There was, however, a notable nonsignificant increase in secretion in the $\mathrm{NCM}$ wells that was suppressed in the presence of $50 \mu \mathrm{M}$ $\mathrm{H}_{2} \mathrm{O}_{2}$.
Pathipati/Ferriero 
Fig. 2. rmEpo effects on NO, ROS, and superoxide levels following $\mathrm{H}_{2} \mathrm{O}_{2}$ injury. Cultured primary murine astrocytes (Ast) and microglia $(\mathrm{Mg})$ were exposed to continuous or bolus $\mathrm{H}_{2} \mathrm{O}_{2}$ for $4 \mathrm{~h}$ before treatment with $10 \mathrm{ng} / \mathrm{mL} \mathrm{rmEpo.} \mathrm{Secreted} \mathrm{NO} \mathrm{levels}$ $(\mathbf{a}, \mathbf{b})$ in the medium were measured using the Griess assay, ROS levels (c, d) were measured using the H2DCFDA indicator, and superoxide levels $(\mathbf{e}, \mathbf{f})$ were measured using the MitoSOX indicator at the end of the study. $\mathrm{H}_{2} \mathrm{O}_{2}$ did not have any significant effects on secreted nitrite levels in either $\mathrm{Mg}$ (a) or Ast (b), but Epo significantly increased the NO levels in the Ast wells. There was significant suppression of microglial ROS and superoxide with Epo treatment at the high continuous dose in $\mathrm{Mg}(\mathbf{c}, \mathbf{e})$ but not in Ast $(\mathbf{d}, \mathbf{f})$. The results presented here are compiled from at least 5 independent assays run in duplicate. ${ }^{*} p<$ $0.05,{ }^{* *} p<0.01$ versus control.
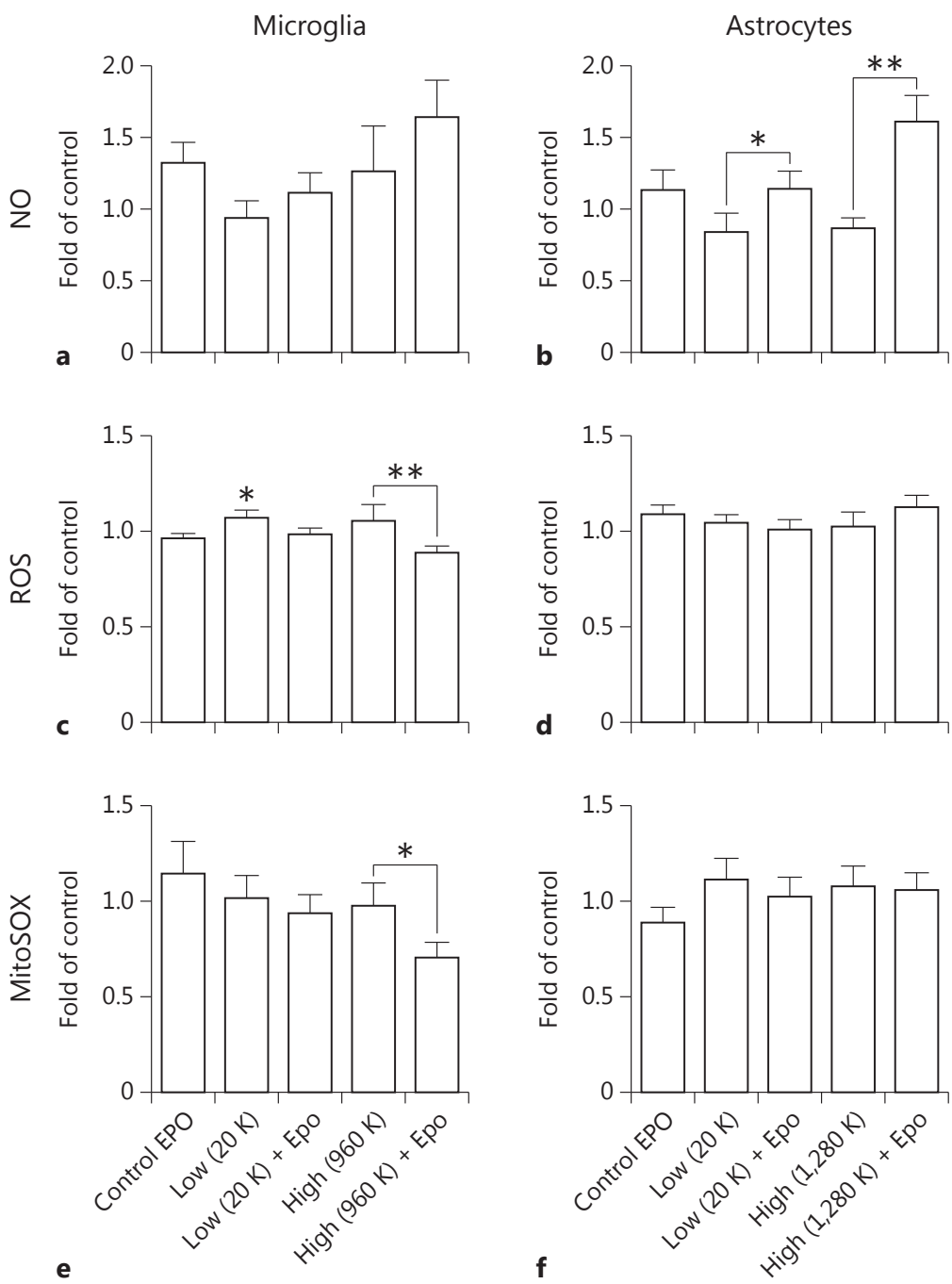

\section{Discussion}

Although there has been much interest in using Epo as a protective and restorative agent after injury to the central nervous system, the response of Ast and Mg to Epo after oxidative stress is largely unknown. Here, we found differential effects in these cell types in terms of viability, oxidative responses, and inflammatory mediator secretion, both without and with the presence of NCM.

\section{Viability}

In the conditions tested in this study, rmEpo did not significantly reduce $\mathrm{H}_{2} \mathrm{O}_{2}$-induced cell death in either cell type when given $4 \mathrm{~h}$ after $\mathrm{H}_{2} \mathrm{O}_{2}$ initiation, even at high $\mathrm{H}_{2} \mathrm{O}_{2}$ levels. There are studies that have shown protection of $\mathrm{Mg}$ with Epo posttreatment up to $6 \mathrm{~h}$ after the insult, but they differ in terms of the type of injury as well as species $[21,23]$, which suggests that Epo-mediated protection in $\mathrm{Mg}$ depends on such factors [20, 21, 23]. In Ast, on the other hand, while there was a trend towards a decrease in cell death after high $\mathrm{H}_{2} \mathrm{O}_{2}$, this failed to reach significance.

In support of previous reports [24], pretreatment reduced LDH release in Ast, but failed to show any effect on $\mathrm{Mg}$ LDH release, which contrasts with previous reports $[21,25]$. While it is possible that the cells were injured 
Fig. 3. a-h Microglial inflammatory mediator responses to $\mathrm{H}_{2} \mathrm{O}_{2}$ stimulation and rmEpo exposure. Cultured primary murine microglia were exposed to continuous $\mathrm{H}_{2} \mathrm{O}_{2}$ for $4 \mathrm{~h}$ before treatment with $10 \mathrm{ng} /$ $\mathrm{mL}$ rmEpo for $20 \mathrm{~h}$. Medium was collected at the end of $20 \mathrm{~h}$ and inflammatory mediator levels were assessed by a 15-plex cytokine/chemokine assay. For clarity, only data with considerable changes are shown here. Final $n=6$ ( 4 for some), data shown are normalized to protein. ${ }^{*} p<0.05$ versus control.

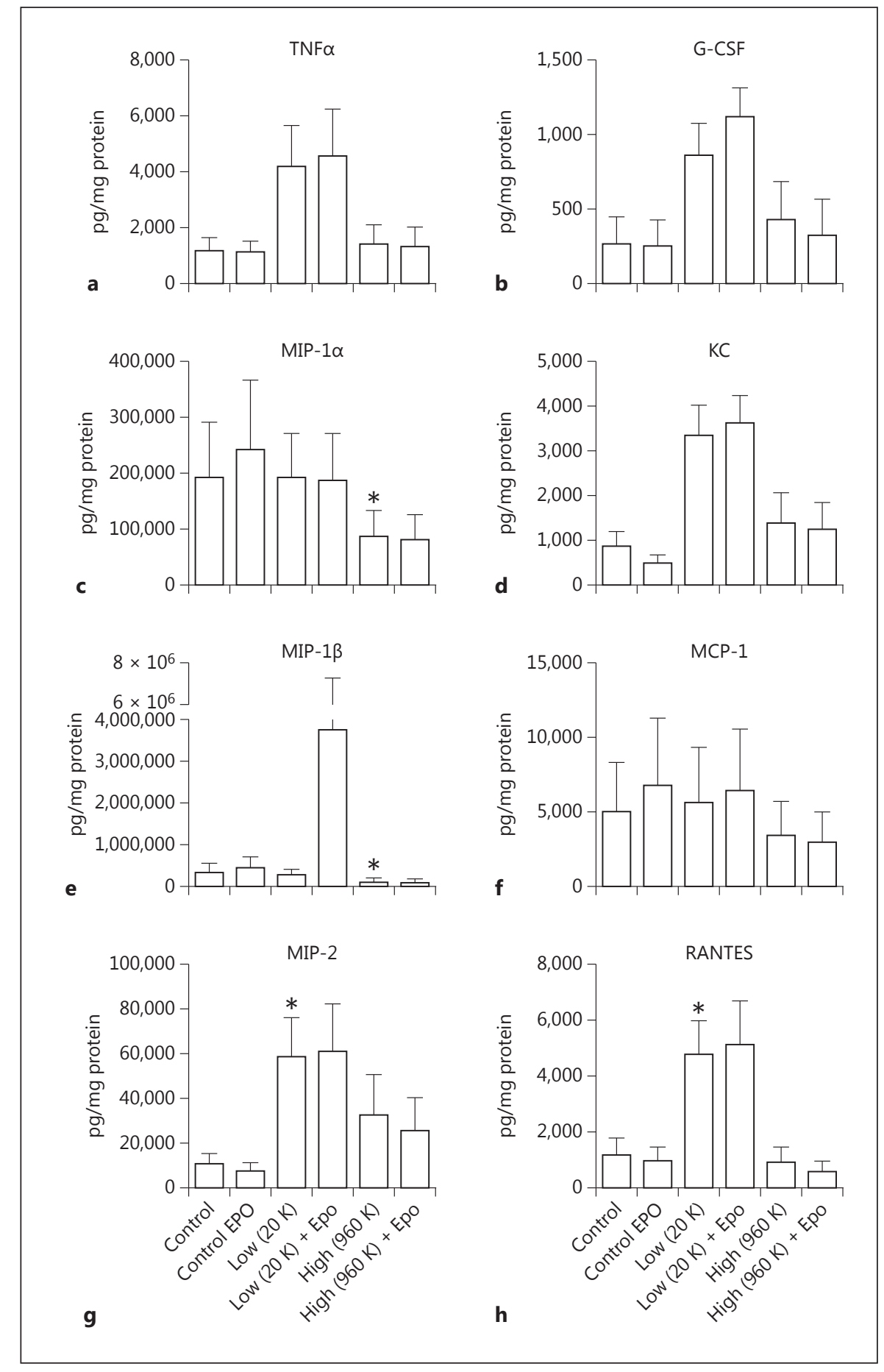

beyond the possibility of repair at the higher concentrations, it is more likely that rmEpo mediates protection primarily in Ast rather than in $\mathrm{Mg}$ after $\mathrm{H}_{2} \mathrm{O}_{2}$ injury. Support for this hypothesis comes from several findings that suggest Epo has pleiotropic effects, depending on cell and injury type [16]. For example, Epo activates the p38MAPK pathway in Ast to preserve their integrity [26, 27], but blocking this pathway in vivo does not affect neuronal survival [28]. Moreover, while it has been identified that Akt1-dependent Epo signaling maintains endothelial cell 


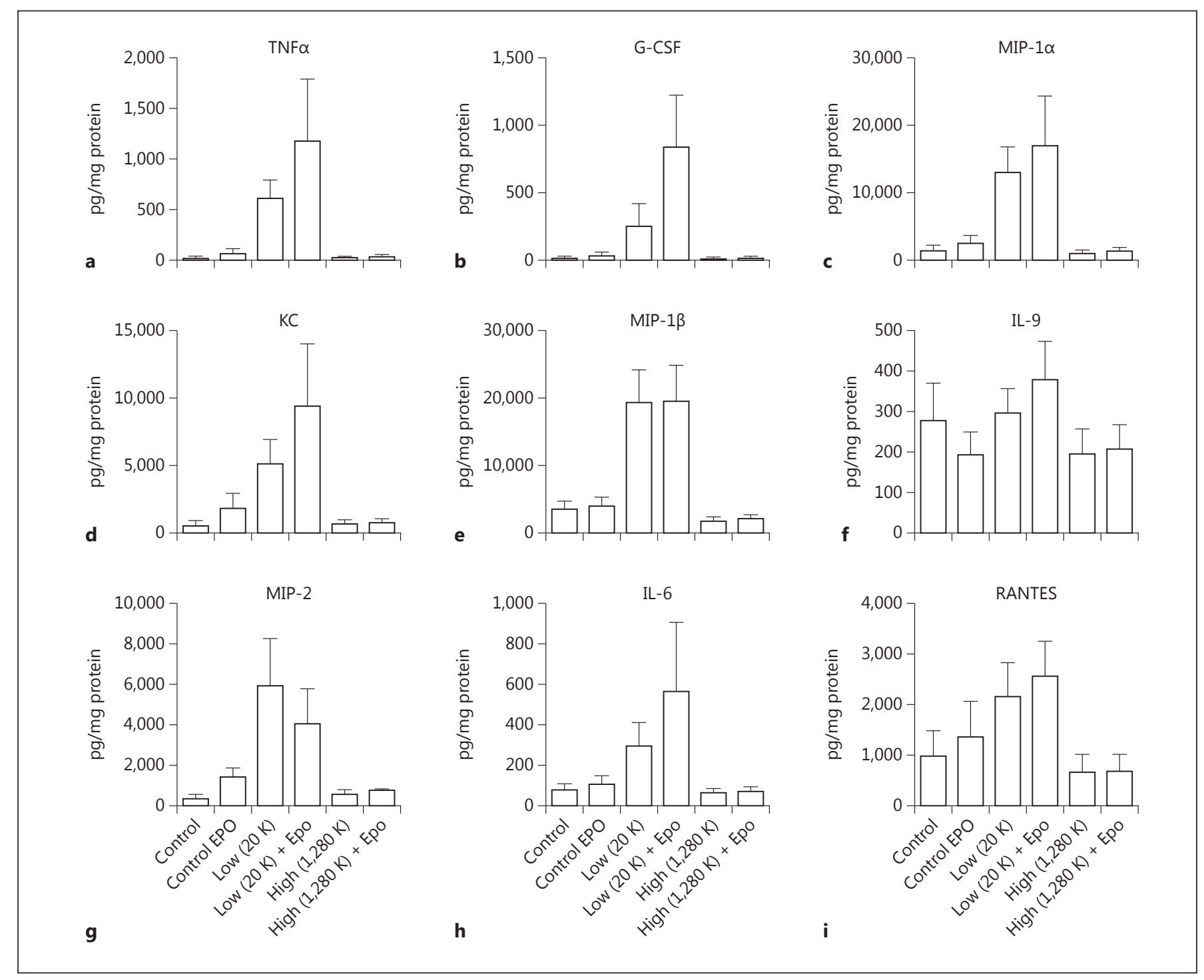

Fig. 4. a-i Astrocytic inflammatory mediator responses in response to $\mathrm{H}_{2} \mathrm{O}_{2}$ stimulation and rmEpo exposure. Cultured primary murine astrocytes were exposed to continuous $\mathrm{H}_{2} \mathrm{O}_{2}$ for $4 \mathrm{~h}$ before treatment with $10 \mathrm{ng} / \mathrm{mL} \mathrm{rmEpo}$ for $20 \mathrm{~h}$. Medium was col- lected at the end of $20 \mathrm{~h}$ and inflammatory mediator levels were assessed by a 15-plex cytokine/chemokine assay. For clarity, only data with considerable changes are shown here. Final $n=6$ (4 for some), data shown are normalized to protein.
[29] and $\mathrm{Mg}[21,25]$ integrity, it does not appear to play a role in Ast neuroprotection [30].

\section{Oxidative Stress}

While $\mathrm{H}_{2} \mathrm{O}_{2}$ can induce cell death in the neonatal brain via the apoptotic death cascade [31], it is known especially for eliciting damaging effects via its reaction with excess free iron (Fenton reaction), leading to the generation of free radicals such as the hydroxyl radical, superoxide, and NO, all of which lead to subsequent damage [17, 32]. Al- though there is some evidence that Epo leads to a decrease in NO levels in $\mathrm{Mg}[23,33]$, most studies have shown that it has no significant effect on $\mathrm{NO}$ production in activated Mg cultures [23, 31-34]. Here, we actually saw an increase in nitrite levels with Epo treatment in both $\mathrm{Mg}$ and Ast (only significant in Ast). Wenker et al. [35], reported increased nitrite production in $\mathrm{Mg}$ after Epo exposure of a microglial cell line, an effect that was lost when an inhibitor of the PI3K pathway was used; a similar mode of action might have been relevant in our study. 


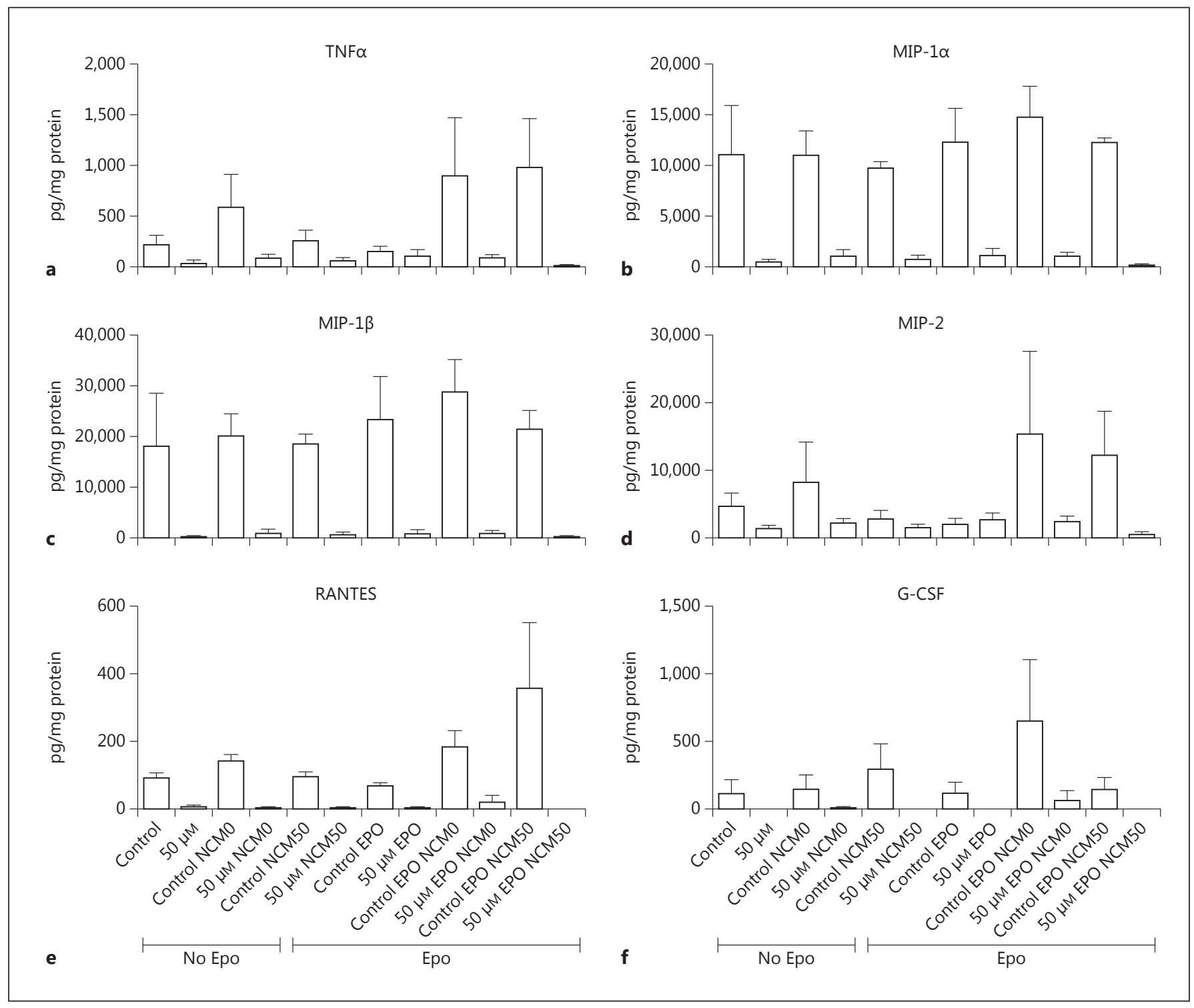

Fig. 5. a-f Microglial inflammatory mediator responses in response to $\mathrm{H}_{2} \mathrm{O}_{2}$ stimulation and rmEpo exposure in the presence of neuron-conditioned medium (NCM). Neurons were exposed to $50 \mu \mathrm{M} \mathrm{H}_{2} \mathrm{O}_{2}$ for $30 \mathrm{~min}$, and the conditioned medium from these cultures was added to cultures of primary murine microglia, which were then exposed to $\mathrm{H}_{2} \mathrm{O}_{2}$ for 4 h before treatment with $10 \mathrm{ng} / \mathrm{mL}$

Other studies have reported a similar Epo-mediated increase in $\mathrm{NO}$ and $\mathrm{NO}$ synthase levels in various tissues $[36,37]$. An increase in NO in endothelial cells is thought to maintain blood pressure homeostasis and blood flow [38], and NO induced in the central nervous system via $\mathrm{HIF}_{1 \alpha}$-mediated Epo production has been shown to prevent axonal degeneration [39]. It is possible that the increase in NO is actually a beneficial manifestation of Epo

rmEpo for $20 \mathrm{~h}$. Medium was collected at the end of $20 \mathrm{~h}$ and inflammatory mediator levels were assessed by a 15-plex cytokine/ chemokine assay. For clarity, only data with considerable changes are shown here. Final $n=3$, data shown are normalized to protein. NCM0, NCM from uninjured neurons; NCM50, NCM from neurons exposed to $50 \mu \mathrm{M}$ of $\mathrm{H}_{2} \mathrm{O}_{2}$.

signaling following oxidative stress. The increase in NO levels with rmEpo treatment was observed only in the cultures exposed to continuous $\mathrm{H}_{2} \mathrm{O}_{2}$ in Ast. Glial cells have been shown to have a high antioxidative capacity $[40,41]$ that renders them highly tolerant to oxidative stress and capable of effectively disposing of oxidants such as $\mathrm{H}_{2} \mathrm{O}_{2}$ within a short time $[42,43]$, which makes sustained $\mathrm{H}_{2} \mathrm{O}_{2}$ production application more relevant 


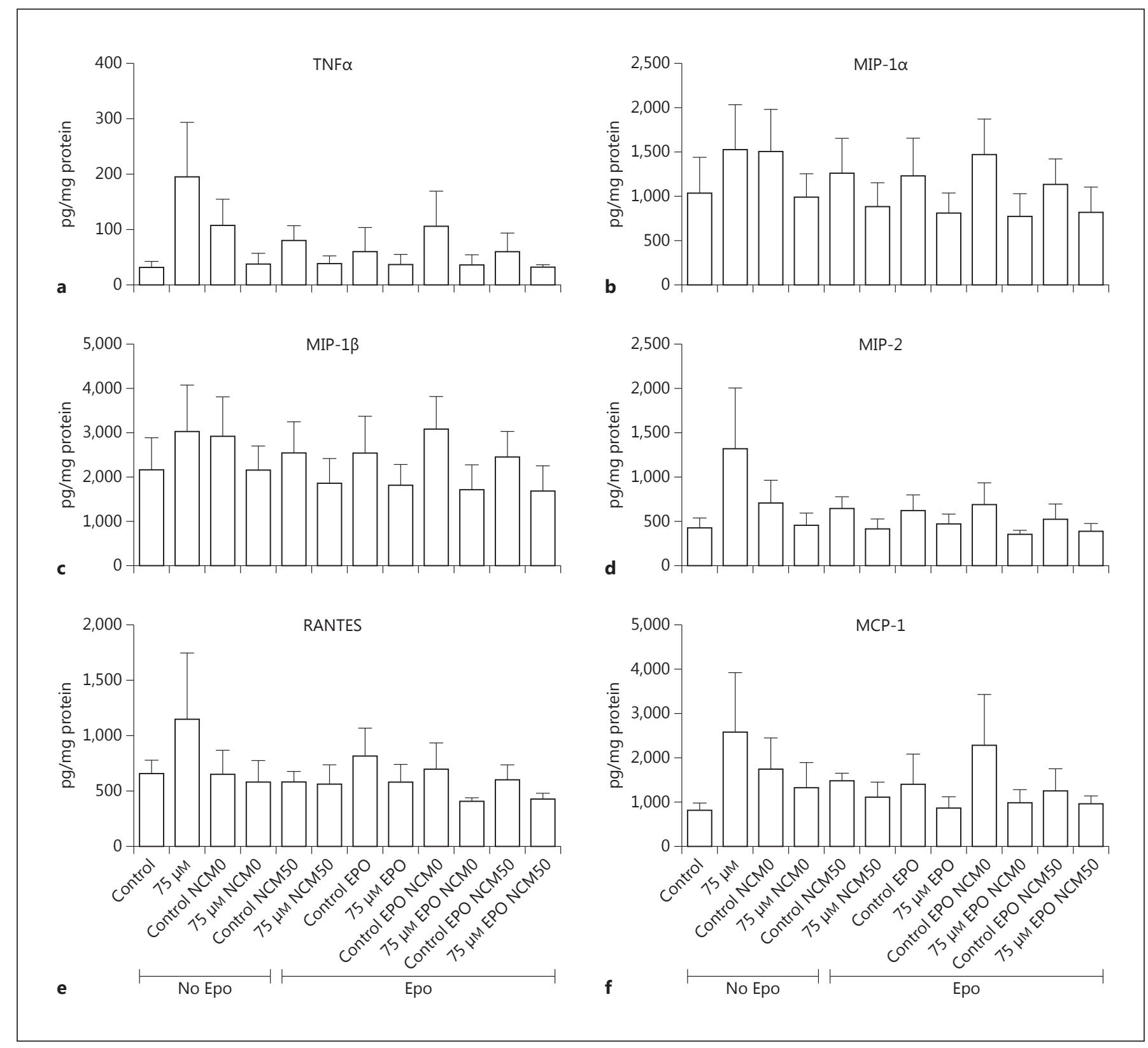

Fig. 6. a-h Astrocytic inflammatory mediator responses in response to $\mathrm{H}_{2} \mathrm{O}_{2}$ stimulation and rmEpo exposure in the presence of neuron-conditioned medium (NCM). Neurons were exposed to $50 \mu \mathrm{M} \mathrm{H}_{2} \mathrm{O}_{2}$ for $30 \mathrm{~min}$, and the conditioned medium from these cultures was added to the cultures of primary murine microglia, which were then exposed to $\mathrm{H}_{2} \mathrm{O}_{2}$ for $4 \mathrm{~h}$ before treatment with 10

$\mathrm{ng} / \mathrm{mL}$ rmEpo for $20 \mathrm{~h}$. Medium was collected at the end of $20 \mathrm{~h}$ and inflammatory mediator levels were assessed by a 15-plex cytokine/chemokine assay. For clarity, only data with considerable changes are shown here. Final $n=3$, data shown are normalized to protein. NCM0, NCM from uninjured neurons; NCM50, NCM from neurons exposed to $50 \mu \mathrm{M}$ of $\mathrm{H}_{2} \mathrm{O}_{2}$.

for studies such as ours. The sustained $\mathrm{H}_{2} \mathrm{O}_{2}$ better mimics the in vivo situation following neonatal $\mathrm{HI}$ insult [17]. Studying the effects of Epo treatment during such an insult yields a much better understanding of the mechanisms of Epo activity.

Erythropoietin and Microglia and Astrocytes

Dev Neurosci 2017;39:310-322

Both ROS and MitoSOX levels were suppressed with rmEpo treatment in continuous $\mathrm{H}_{2} \mathrm{O}_{2}$-exposed $\mathrm{Mg}$, highlighting an antioxidative role for rmEpo that other studies reported previously [44]. There was, however, no significant change in the ROS levels in Ast, supporting sugges-

DOI. $10.1159 / 000467391$ 
tions that Epo appears to act via various mechanisms depending on the individual cell and injury types [16]. This finding is in contradiction to that reported by Liu et al. [45], who showed an amelioration of MitoSOX indicator levels with Epo treatment following paraquat-induced oxidative stress in Ast. It is likely that the difference between the 2 studies regarding the type of injury accounts for these disparate findings [46].

\section{Inflammation}

rmEpo treatment failed to elicit any significant effects on the levels of secreted cytokines and chemokines in both cell types. Low continuous $\mathrm{H}_{2} \mathrm{O}_{2}$ elicited the maximal statistically significant responses in chemokine levels (MIP-2 and RANTES) in Mg, as we reported previously with similar nonsignificant effects in Ast for the same chemokines (MIP-1 $\alpha$, MIP- $1 \beta$, MIP-2, and RANTES) as well as for KC and G-CSF [18]. This reflects previous findings that $\mathrm{H}_{2} \mathrm{O}_{2}$, acting as a second messenger, induces chemokine responses $[47,48]$. Chemokine expression is an important mediator of the proliferation, recruitment, and migration of $\mathrm{Mg}$, as well as of other immune and stem cells which provide for the containment and resolution of injury [49-51]. It appears that low continuous $\mathrm{H}_{2} \mathrm{O}_{2}$, which we presume is functioning as a signaling molecule, acts to provide preconditioning protection [52]. In addition to the above chemokine responses, Ast also had disparate responses to certain cytokines such as G-CSF, IL-6, and IL-4, which were unresponsive in Mg. This discrepancy in inflammatory responses is an indication of the variation in responses of both cell types to injury. For example, a previous study showed that endotoxin stimulated $\mathrm{Mg}$ to produce 95 times more $\mathrm{TNF} \alpha$ than did Ast [53]. Ultimately, there was no apparent antior proinflammatory effect for either cell type in response to $\mathrm{H}_{2} \mathrm{O}_{2}$, or, more importantly, to Epo. While the lack of an anti-inflammatory effect for Epo in $\mathrm{Mg}$ has already been widely established $[23,33,34]$, to our knowledge, this is the first study to report cytokine/chemokine secretion by Ast in response to Epo treatment following $\mathrm{H}_{2} \mathrm{O}_{2}$ injury. This suggests that Epo-mediated neuroprotection is a result of mechanisms other than those directly mediating inflammation, at least in the paradigms tested in this study.

While the presence of NCM augmented the levels of chemokines (MIP-1 $\alpha$, MIP-1 $\beta$, and RANTES) secreted in the microglial cells, the presence of $\mathrm{H}_{2} \mathrm{O}_{2}$ appeared to dampen this augmentation. This is somewhat surprising, considering that $\mathrm{H}_{2} \mathrm{O}_{2}$ has been established as a chemokine-inducing factor [47]. The fact that the presence of
NCM itself was sufficient to elicit this increase, regardless of whether it was from uninjured or injured neurons, points to the importance of cell-to-cell signaling in the brain, i.e., that $\mathrm{Mg}$ secretory responses are enhanced in the presence of neuronal communication (not significant with the Wilcoxon test). Chong et al. [25] showed that there was an increase in $\mathrm{Mg}$ proliferation and phosphatidyl serine receptor expression in response to NCM from injured neurons, a phenomenon that could be blocked by Epo pretreatment. In our study, rmEpo treatment did not appear to have any significant effect on $\mathrm{Mg}$ exposed to NCM, suggesting that (1) pretreatment with rmEpo would be more effective or (2) rmEpo does not modulate cytokine/chemokine responses in $\mathrm{Mg}$.

A similar dampening of NCM-augmented secretory responses was evident in Ast treated with $\mathrm{H}_{2} \mathrm{O}_{2}$, although on a much lower scale, suggesting that the mechanisms involved were similar to those in $\mathrm{Mg}$, despite $\mathrm{Mg}$ being much more responsive to NCM than Ast. The addition of NCM suppressed MIP-2 and TNFa levels considerably, suggesting that the presence of neurons dampens $\mathrm{H}_{2} \mathrm{O}_{2}$-induced MIP-2 and TNFa levels. Both MIP-2 and TNFa have been shown to be produced in response to injury [54], with deleterious effects. Modulation of their secreted levels in the presence of NCM suggests that neuronal communication is an important factor controlling their secretion, potentially ameliorating a harmful response.

In conclusion, it appears that rmEpo-mediated cellular effects are pleiotropic and multifaceted, depending not only on the cell type but also on the mode and level of injury and treatment. In terms of the oxidative and secretory responses of $\mathrm{Mg}$ and Ast, rmEpo appears to have largely similar effects on both cell types, some of which are significantly different to those reported in the neurons. Ultimately, this study highlights the importance of taking into careful consideration multiple necessary factors, which, cohesively, could predict the optimal use of Epo following injury.

\section{Acknowledgements}

We sincerely thank Dr. Xiangning Jiang for her comments on the manuscript and Assoc. Prof. David Glidden for advice with statistical analysis.

\section{Funding Source}

This work was supported by funding from Fondation LeDucq (10 CVD-01) and RO1 033997.
Pathipati/Ferriero 


\section{References}

1 Glass HC, Costarino AT, Stayer SA, Brett CM, Cladis F, Davis PJ: Outcomes for extremely premature infants. Anesth Analg 2015;120: 1337-1351.

2 Pappas A, Shankaran S, McDonald SA, Vohr BR, Hintz SR, Ehrenkranz RA, et al: Cognitive outcomes after neonatal encephalopathy. Pediatrics 2015;135:e624-e634.

3 Sheldon RA, Jiang X, Francisco C, Christen S, Vexler ZS, Täuber MG, et al: Manipulation of antioxidant pathways in neonatal murine brain. Pediatr Res 2004;56:656-662.

4 Lafemina MJ, Sheldon RA, Ferriero DM: Acute hypoxia-ischemia results in hydrogen peroxide accumulation in neonatal but not adult mouse brain. Pediatr Res 2006;59:680683.

5 Tataranno ML, Perrone S, Longini M, Buonocore G: New antioxidant drugs for neonatal brain injury. Oxid Med Cell Longev 2015; 2015:108251

6 Juul SE, Yachnis AT, Christensen RD: Tissue distribution of erythropoietin and erythropoietin receptor in the developing human fetus. Early Hum Dev 1998;52:235-249.

7 Marti HH, Wenger RH, Rivas LA, Straumann U, Digicaylioglu M, Henn V, et al: Erythropoietin gene expression in human, monkey and murine brain. Eur J Neurosci 1996;8:666676.

8 Sugawa M, Sakurai Y, Ishikawa-Ieda Y, Suzuki H, Asou H: Effects of erythropoietin on glial cell development; oligodendrocyte maturation and astrocyte proliferation. Neurosci Res 2002;44:391-403.

9 Wallach I, Zhang J, Hartmann A, van Landeghem FKH, Ivanova A, Klar M, et al: Erythropoietin-receptor gene regulation in neuronal cells. Pediatr Res 2009;65:619-624.

10 Gonzalez FF, Larpthaveesarp A, McQuillen P, Derugin N, Wendland M, Spadafora R, et al: Erythropoietin increases neurogenesis and oligodendrogliosis of subventricular zone precursor cells after neonatal stroke. Stroke 2013;44:753-758.

11 Nagai A, Nakagawa E, Choi HB, Hatori K, Kobayashi S, Kim SU: Erythropoietin and erythropoietin receptors in human CNS neurons, astrocytes, microglia, and oligodendrocytes grown in culture. J Neuropathol Exp Neurol 2001;60:386-392.

12 Spandou E, Papoutsopoulou S, Soubasi V, Karkavelas G, Simeonidou C, Kremenopoulos G, et al: Hypoxia-ischemia affects erythropoietin and erythropoietin receptor expression pattern in the neonatal rat brain. Brain Res 2004;1021:167-172.

13 Jantzie LL, Miller RH, Robinson S: Erythropoietin signaling promotes oligodendrocyte development following prenatal systemic hypoxic-ischemic brain injury. Pediatr Res 2013;74:658-667.
14 Xiong Y, Mahmood A, Meng Y, Zhang Y, Qu C, Schallert T, et al: Delayed administration of erythropoietin reducing hippocampal cell loss, enhancing angiogenesis and neurogenesis, and improving functional outcome following traumatic brain injury in rats: comparison of treatment with single and triple dose. J Neurosurg 2010;113:598-608.

15 Rangarajan V, Juul SE: Erythropoietin: emerging role of erythropoietin in neonatal neuroprotection. Pediatr Neurol 2014;51: 481-488.

16 Bond WS, Rex TS: Evidence that erythropoietin modulates neuroinflammation through differential action on neurons, astrocytes, and microglia. Front Immunol 2014;5:523.

17 Lafemina MJ, Sheldon RA, Ferriero DM: Acute hypoxia-ischemia results in hydrogen peroxide accumulation in neonatal but not adult mouse brain. Pediatr Res 2006;59:680683.

18 Pathipati P, Müller S, Jiang X, Ferriero D: Phenotype and secretory responses to oxidative stress in microglia. Dev Neurosci 2013;35: 241-254.

19 Mueller S, Millonig G, Waite GN: The GOX/ CAT system: a novel enzymatic method to independently control hydrogen peroxide and hypoxia in cell culture. Adv Med Sci 2009;54: 121-135.

20 Shang YC, Chong ZZ, Wang S, Maiese K: Prevention of $\beta$-amyloid degeneration of microglia by erythropoietin depends on Wnt1, the PI 3-K/mTOR pathway, Bad, and Bcl-xL. Aging (Albany NY) 2012;4:187-201.

21 Li F, Chong ZZ, Maiese K: Microglial integrity is maintained by erythropoietin through integration of Akt and its substrates of glycogen synthase kinase- $3 \beta$, $\beta$-catenin, and NF$\kappa B$. Curr Neurovasc Res 2006;3:187-201.

22 Girouard H, Wang G, Gallo EF, Anrather J, Zhou P, Pickel VM, et al: NMDA receptor activation increases free radical production through nitric oxide and NOX2. J Neurosci 2009;29:2545-2552.

23 Vairano M, Dello Russo C, Pozzoli G, Battaglia A, Scambia G, Tringali G, et al: Erythropoietin exerts anti-apoptotic effects on rat microglial cells in vitro. Eur J Neurosci 2002;16: 684-692.

24 Brines M, Grasso G, Fiordaliso F, Sfacteria A, Ghezzi P, Fratelli M, et al: Erythropoietin mediates tissue protection through an erythropoietin and common beta-subunit heteroreceptor. Proc Natl Acad Sci USA 2004;101: 14907-14912.

25 Chong ZZ, Kang J-Q, Maiese K: Erythropoietin fosters both intrinsic and extrinsic neuronal protection through modulation of microglia, Akt1, Bad, and caspase-mediated pathways. Br J Pharmacol 2003;138:11071118 .
26 Chu H, Ding H, Tang Y, Dong Q: Erythropoietin protects against hemorrhagic bloodbrain barrier disruption through the effects of aquaporin-4. Lab Invest 2014;94:1042-1053.

27 Tang Z, Sun X, Huo G, Xie Y, Shi Q, Chen S, et al: Protective effects of erythropoietin on astrocytic swelling after oxygen-glucose deprivation and reoxygenation: mediation through AQP4 expression and MAPK pathway. Neuropharmacology 2013;67:8-15.

28 Sättler MB, Merkler D, Maier K, Stadelmann C, Ehrenreich H, Bähr M, et al: Neuroprotective effects and intracellular signaling pathways of erythropoietin in a rat model of multiple sclerosis. Cell Death Differ 2004;11 (suppl 2):S181-S192.

29 Chong ZZ, Kang JQ, Maiese K: Erythropoietin is a novel vascular protectant through activation of Akt1 and mitochondrial modulation of cysteine proteases. Circulation 2002; 106:2973-2979.

30 Diaz Z, Assaraf MI, Miller WH, Schipper HM: Astroglial cytoprotection by erythropoietin pre-conditioning: implications for ischemic and degenerative CNS disorders. J Neurochem 2005;93:392-402.

31 Whittemore ER, Loo DT, Watt JA, Cotmans CW: A detailed analysis of hydrogen peroxide-induced cell death in primary neuronal culture. Neuroscience 1995;67:921-932.

32 Lu Q, Harris VA, Rafikov R, Sun X, Kumar S, Black SM: Nitric oxide induces hypoxia ischemic injury in the neonatal brain via the disruption of neuronal iron metabolism. Redox Biol 2015;6:112-121.

33 Digicaylioglu M, Lipton SA: Erythropoietinmediated neuroprotection involves cross-talk between Jak2 and NF- $\kappa \mathrm{B}$ signalling cascades. Nature 2001;412:641-647.

34 Wilms H, Schwabedissen B, Sievers J, Lucius R: Erythropoietin does not attenuate cytokine production and inflammation in microglia implications for the neuroprotective effect of erythropoietin in neurological diseases. J Neuroimmunol 2009;212:106-111.

35 Wenker SD, Chamorro ME, Vittori DC, Nesse AB: Protective action of erythropoietin on neuronal damage induced by activated $\mathrm{mi}$ croglia. FEBS J 2013;280:1630-1642.

$36 \mathrm{Su} \mathrm{KH}$, Shyue SK, Kou YR, Ching LC, Chiang $\mathrm{AN}, \mathrm{Yu} \mathrm{Y}$, et al: $\beta$ Common receptor integrates the erythropoietin signaling in activation of endothelial nitric oxide synthase. J Cell Physiol 2011;226:3330-3339.

37 Teng R, Calvert JW, Sibmooh N, Piknova B, Suzuki N, Sun J, et al: Acute erythropoietin cardioprotection is mediated by endothelial response. Basic Res Cardiol 2011;106:343354.

38 Beleslin-Cokic BB, Cokic VP, Yu X, Weksler BB, Schechter AN, Noguchi CT: Erythropoietin and hypoxia stimulate erythropoietin receptor and nitric oxide production by endothelial cells. Blood 2004;104:2073-2080.
Erythropoietin and Microglia and Astrocytes
Dev Neurosci 2017;39:310-322

DOI: $10.1159 / 000467391$
321 
39 Keswani SC, Bosch-Marcé M, Reed N, Fischer A, Semenza GL, Höke A: Nitric oxide prevents axonal degeneration by inducing HIF1-dependent expression of erythropoietin. Proc Natl Acad Sci USA 2011;108:4986-4990.

40 Liddell JR, Robinson SR, Dringen R: Endogenous glutathione and catalase protect cultured rat astrocytes from the iron-mediated toxicity of hydrogen peroxide. Neurosci Lett 2004;364:164-167.

41 Dringen R: Oxidative and antioxidative potential of brain microglial cells. Antioxid Redox Signal 2012;7:1223-1233.

42 Hirrlinger J, Hamprecht B, Dringen R: Application and modulation of a permanent hydrogen peroxide-induced oxidative stress to cultured astroglial cells. Brain Res Protoc 1999;4: 223-229.

43 Dringen R, Pawlowski PG, Hirrlinger J: Peroxide detoxification by brain cells. J Neurosci Res 2005;79:157-165.

44 Katavetin P, Tungsanga K, Eiam-Ong S, Nangaku M: Antioxidative effects of erythropoietin. Kidney Int Suppl 2007;107:S10-S15.
45 Liu J, Narasimhan P, Song YS, Nishi T, Yu F, Lee YS, et al: Epo protects SOD2-deficient mouse astrocytes from damage by oxidative stress. Glia 2006;53:360-365.

46 Angelova MB, Pashova SB, Spasova BK, Vassilev SV, Slokoska LS: Oxidative stress response of filamentous fungi induced by hydrogen peroxide and paraquat. Mycol Res 2005;109:150-158.

47 Jaramillo M, Olivier M, Alerts E: Hydrogen peroxide induces murine macrophage chemokine gene transcription via extracellular signal-regulated kinase- and cyclic adenosine $5^{\prime}$-monophosphate (cAMP)-dependent pathways: involvement of NF- $\mathrm{kB}$, activator protein 1, and cAMP response element binding. J Immunol 2002;169:7026-7038.

48 Hara-Chikuma M, Chikuma S, Sugiyama Y, Kabashima K, Verkman AS, Inoue S, et al: Chemokine-dependent $\mathrm{T}$ cell migration requires aquaporin-3-mediated hydrogen peroxide uptake. J Exp Med 2012;209:17431752.
49 Belmadani A, Tran PB, Ren D, Miller RJ: Chemokines regulate the migration of neural progenitors to sites of neuroinflammation. J Neurosci 2006;26:3182-3191.

50 Hinojosa AE, Garcia-Bueno B, Leza JC, Madrigal JLM: CCL2/MCP-1 modulation of microglial activation and proliferation. J Neuroinflammation 2011;8:77.

51 Bruno V, Copani A, Besong G, Scoto G, Nicoletti F: Neuroprotective activity of chemokines against $\mathrm{N}$-methyl-D-aspartate or $\beta$ amyloid-induced toxicity in culture. Eur J Pharmacol 2000;399:117-121.

52 Pathipati P, Surus A, Williams CE, Scheepens A: Delayed and chronic treatment with growth hormone after endothelin-induced stroke in the adult rat. Behav Brain Res 2009; 204:93-101.

53 Malipiero UV, Frei K, Fontana A: Production of hemopoietic colony-stimulating factors by astrocytes. J Immunol 1990;144:3816-3821.

54 Liu F, McCullough LD: Inflammatory responses in hypoxic ischemic encephalopathy. Acta Pharmacol Sin 2013;34:1121-1130. 